\title{
The special role of ultrasound for screening, staging and surveillance of malignant ovarian tumors: distinction from other methods of diagnostic imaging
}

\author{
Gwendolin Manegold-Brauer • Anjeung Kang Bellin • \\ Sevgi Tercanli · Olav Lapaire $\cdot$ Viola Heinzelmann-Schwarz
}

Received: 30 May 2013/Accepted: 29 October 2013/Published online: 20 November 2013

(C) Springer-Verlag Berlin Heidelberg 2013

\begin{abstract}
Ovarian cancer is the most aggressive gynecologic malignancy, with a 5-year survival rate ranging around $40 \%$. A crucial factor influencing the prognosis is early detection of a suspicious mass and referral to a gynecologic oncology center for further diagnosis, staging and debulking surgery. Here, we present the different imaging methods ultrasound (US), magnetic resonance imaging, computer tomography (CT) and 18F-fluorodeoxyglucose positron emission tomography (PET)/CT that are used for the characterization, diagnosis, staging and surveillance of ovarian cancer. In this review, we focus on US and discuss in detail the advantages and the limitations, as well as the appropriate indications for each of the individual imaging techniques.
\end{abstract}

Keywords Ovarian cancer - Diagnostic imaging · Adnexal mass $\cdot$ Transvaginal ultrasound $\cdot$ Staging ovarian cancer

\section{Introduction}

Ovarian cancer is the fifth most common gynecological cancer. It is the most aggressive gynecologic malignancy,

G. Manegold-Brauer $(\bowtie) \cdot$ O. Lapaire .

V. Heinzelmann-Schwarz

Ultrasound Unit, Department of Gynecology and Obstetrics,

University Hospital of Basel, Basel, Switzerland

e-mail: gwendolin.manegold-brauer@usb.ch

A. K. Bellin · S. Tercanli

Practice for Prenatal Diagnostics and Gynecologic Ultrasound,

Basel, Switzerland with a 5-year survival rate of $\sim 40 \%$. In Europe, $\sim 41900$ women are diagnosed with ovarian cancer and 29200 women die from this disease each year. Over $90 \%$ of the cancers occur sporadically, mainly in postmenopausal women [1], although recent evidence suggests that serous ovarian cancer might be hereditary in up to $44 \%$ of cases [2].

Despite advances in surgery, chemotherapy and intensive ongoing research, survival has not significantly increased. The most important factor for survival is the disease stage at diagnosis. About two-thirds of the patients are diagnosed with advanced disease, which may explain the low-survival rate. When the disease is diagnosed at FIGO stage I, the 5-year survival is around $90 \%$. One reason for the late detection of ovarian cancer is its asymptomatic nature until later stages and its location deep in the pelvis. It is often not detected during the general clinical examinations, and careful gynecological assessments are crucial.

Once a suspicious mass is detected, an important factor influencing the prognosis of ovarian cancer patients is the referral to a gynecologic oncology center for further diagnosis/staging, debulking surgery and interdisciplinary tumor board evaluations [3-5].

Diagnostic imaging has challenges and functions in the detection, staging, preoperative planning and surveillance after initial therapy. Each of the available imaging techniques for assessment of ovarian cancer such as ultrasound (US), computed tomography (CT), magnetic resonance imaging (MRI) and positron emission tomography (PET)/CT has its special advantages and limitations. Our goal was to present and evaluate the different imaging techniques and their role in the characterization of ovarian cancer. 


\section{Diagnosing ovarian cancer}

The role of US in the characterization of complex ovarian masses

The most widely available technique for imaging of the pelvic organs is transvaginal sonography. It has various clinical indications and is used in every day practice to further evaluate pain, irregular bleeding and many other gynecological symptoms. With transvaginal US, most adnexal masses can be identified, many of which are incidental findings. Since ovarian tumors have a wide morphological spectrum and vary highly in appearance and in the degree of malignancy, an accurate systematic approach is important [6]. Benign ovarian lesions are more common than carcinoma, and for this much larger, nonmalignant group, it is important to reduce unnecessary interventions without putting the patient at risk for advanced stage disease. In a recent study exploring the risk of malignancy in a screening program in postmenopausal women, as many as $9 \%$ presented with an adnexal mass [7]. Many different factors can be used to discriminate between benign and malignant adnexal lesions. These include personal and family history, including menopausal status, clinical examination, tumor markers (CA125, HE4), and most importantly, a wide range of different morphological US features (Table 1). Among these US features are the maximal diameter of the adnexal lesion, the presence of ascites, the presence of solid and cystic components and the maximal diameter of any solid components. Furthermore, irregular and smooth cyst walls, the presence of complete and incomplete septa, unilocular and multilocular cysts and the presence of acoustic shadows are used to describe the morphology of a lesion. Doppler US is used to assess the blood flow within a papillary structure and the color score of intra-tumoral blood flow [8]. Table 1 presents simple US characteristics developed by the International Ovarian Tumor Analysis (IOTA) group. These simple rules can be used to characterize adnexal masses as benign or malignant, and can be used as a triage test. Further evaluation through an expert sonographer is necessary in cases of unclassified lesions [9].

More than 90 different prediction models to estimate the risk for malignancy based on the above mentioned features have been developed, but only very few have been confirmed in external validations [10]. The British Royal College of Obstetricians and Gynaecologists (RCOG) has published a guideline for the evaluation of an adnexal finding in postmenopausal women which includes an algorithm to distinguish between benign and malignant adnexal masses. The RCOG recommends calculating the risk of malignancy index (RMI) [11] to decide how to triage the patients according to the score. The RMI has reported and validated sensitivities of 78-85\% and specificities ranging from 77 to $97 \%$ [10-12]. The RMI is a numeric score that takes into account the CA125 level in the serum $(\mathrm{kU} / \mathrm{l})$, menopausal status (premenopausal $=1$, postmenopausal $=3$ ) and morphologic US score with one point for the presence of any of the following characteristics: multilocularity, evidence of solid components, evidence of metastasis, presence of ascites and presence of bilateral lesions. The RMI is calculated according to the following formula: $\mathrm{U}$ (US features) $\times \mathrm{M}$ (menopausal status) $\times$ absolute CA125 value.

For more than a decade, the IOTA group has been working on developing algorithms to calculate the risk of malignancy for adnexal masses based on clinical information and US features. The idea was to design algorithms that could be used by non-expert sonographers. Many studies on the performance of these algorithms have been published [6, 13-15]. In a recent study from 2012, Van Calster et al. [16] compared the IOTA model LR 2 to the current RCOG guidelines and found that the IOTA protocol was superior to the RMI-based RCOG model. According to IOTA estimates, more women would undergo minimally invasive surgery for appropriate reasons, while most invasive cancers would still be correctly referred to a gynecologic oncologist. The main limitation to this study, however, is the fact that experienced sonographers performed all US examinations. As pattern recognition by gray-scale US through an expert sonographer has a sensitivity of $83 \%$ and a specificity of around $90 \%$, it is still superior to all of the known other models developed by the IOTA group and also presumably better than RMI [14]. Another study by the same group reported on the performance of 11 IOTA and non-IOTA models and found that the IOTA models were better in detecting stage I disease, with the best performance in premenopausal women [15]. Whether or not these studies will change the current guidelines remains to be seen.

In addition to US evaluation, new tumor markers have been introduced into clinical practice, the most promising of these being human epididymis protein 4 (HE4). A new algorithm based on the serum markers CA125 and HE4 and menopausal status without US was introduced as the risk of ovarian malignancy algorithm (ROMA) [17]. Although HE4 seems to be effective as a second-line screening marker and has similar performance as CA125, the cost benefit of ROMA and HE4 alone and its routine use in clinical practice are controversial and the right indication for its use remains to be found [18-20].

It is important to remember that all of the US models were created after the decision for surgery had already been made, and there is no information on the outcome of the patients that had been triaged for expectant management. Since benign findings are very common, a model 
Table 1 Simple ultrasound based features for the diagnosis of ovarian cancer according to IOTA [9]

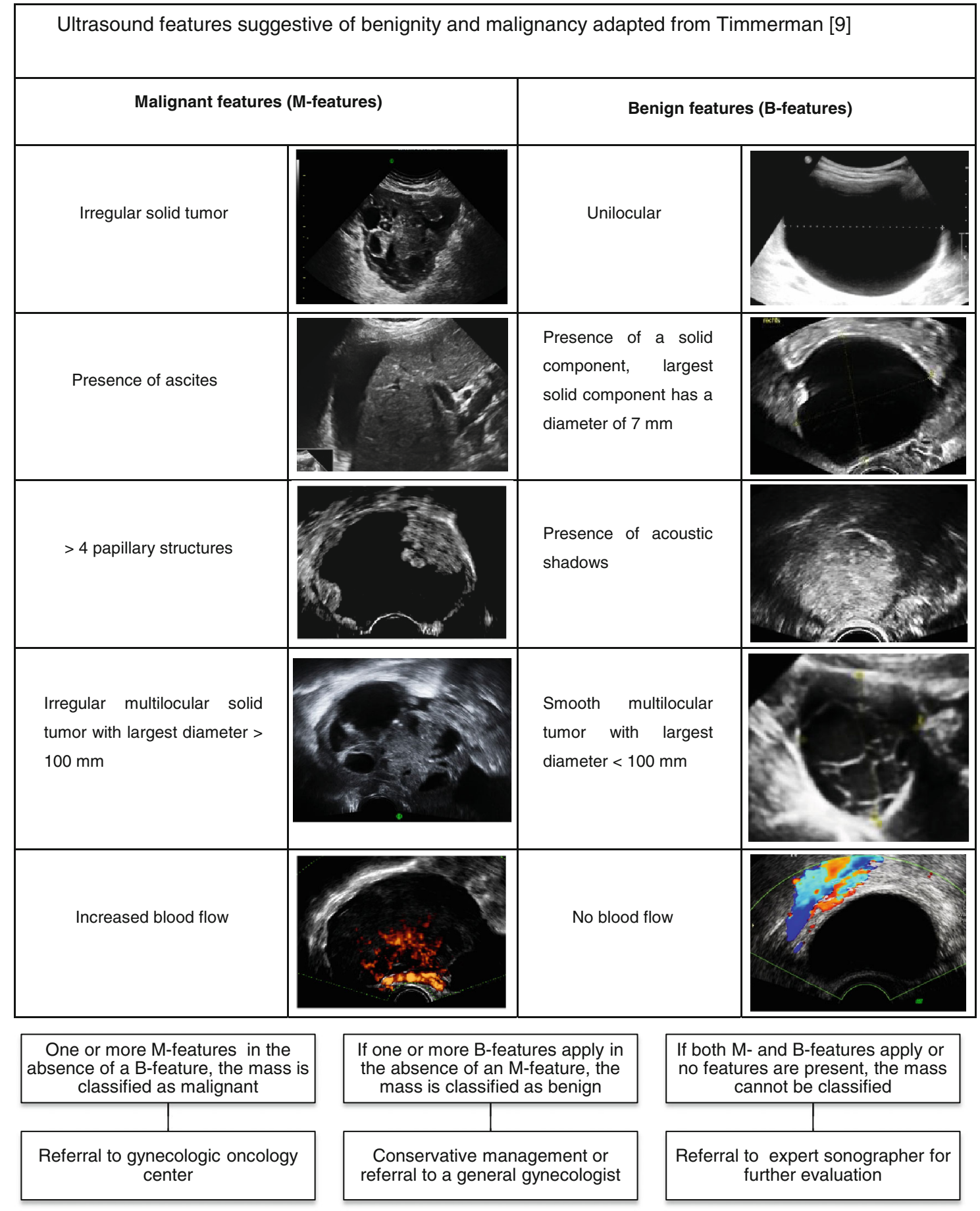

developed to triage women either to expectant management or to surgical management is the most important question remaining [21]. We hope to find answers from another large study from the IOTA group studying the long-term behavior of expectantly managed adnexal pathology in the near future.
At the moment, the preoperative diagnosis of malignancy in persistent adnexal masses by transvaginal US remains a descriptive approach, yet there is no evidence that any other imaging modality performs better than US for this purpose [21]. Due to its ability to image the ovaries in close proximity, transvaginal US gives the most detailed 
information on the internal structure of ovarian masses (Table 1).

As far as screening for ovarian cancer by transvaginal ultrasound is concerned, evidence from large randomized trials could not demonstrate improved survival in asymptomatic women [22]. However, for women with a high genetic risk for ovarian cancer, transvaginal ultrasonography every 6 months and CA125 measurements are recommended by the National Comprehensive Cancer Network although evidence for this strategy is lacking. Results from the UK familial ovarian cancer study intended to answer this question will be available in 2014 [23].

As transvaginal US is a comparably inexpensive imaging method and is readily available in nearly every gynecological unit, it remains the initial and most important imaging method for the detection of adnexal masses and thus for the detection of ovarian cancer.

The role of other imaging methods in characterizing adnexal masses

Magnetic resonance imaging is now considered as a reliable tool for the evaluation of gynecological conditions. It can be used for diagnosis of adnexal lesions and for tumor staging. If a lesion cannot be sufficiently classified by US, conventional and contrast material-enhanced MR imaging can help to determine certain morphological features of the adnexal mass. MRI can differentiate fat, blood and fibrous content based on the signal characteristics of adnexal masses. Conventional MR imaging sequences include $\mathrm{T} 1, \mathrm{~T} 2$ and fat suppressed T1-weighted images. Certain findings characteristic for benign lesions include high signal intensity on T1weighted images and low signal intensity on T2-weighted images. Malignant morphologic features include the presence of solid and cystic areas within a mass, necrosis within a solid lesion, septations, irregular septa, thickened septations, ascites, peritoneal disease, lymphadenopathy and bilateral lesions. Diffusion-weighted imaging has a limited but useful role in evaluating adnexal masses. Adnexal masses with a hypointense solid area on both diffusion-weighted and T2-weighted images are more likely to be benign, whereas those that are hyperintense on diffusion-weighted images with intermediate signal intensity on T2-weighted images are more likely to be malignant [24].

A recent meta-analysis of 22 studies on the performance of MRI in diagnosing adnexal masses found an overall sensitivity of $91.9 \%$ and a specificity of $88.4 \%$ (Table 2) [25].

Another meta-analysis analyzed the value of CT, Doppler US and MRI as assessment models in cases where US was inconclusive. They showed that MR imaging is preferable to combined gray-scale and Doppler US and to CT for the diagnosis of ovarian
Table 2 Reported quality of imaging methods for classifying an adnexal mass

\begin{tabular}{llll}
\hline & $\begin{array}{l}\text { Sensitivity } \\
(\%)\end{array}$ & $\begin{array}{l}\text { Specificity } \\
(\%)\end{array}$ & Citation \\
\hline Ultrasound (US) & 96.0 & 90.0 & $\begin{array}{c}\text { Timmerman } \\
\text { et al. [25] }\end{array}$ \\
$\begin{array}{l}\text { Computer tomography } \\
\text { (CT) }\end{array}$ & 87.2 & 84.0 & $\begin{array}{c}\text { Dodge et al. } \\
{[26]}\end{array}$ \\
$\begin{array}{l}\text { Magnetic resonance } \\
\text { imaging (MRI) }\end{array}$ & 91.9 & 88.4 & $\begin{array}{c}\text { Dodge et al. } \\
{[26]}\end{array}$ \\
$\begin{array}{l}\text { 18 F-fluoro-deoxyglucose } \\
\text { positron emission }\end{array}$ & 97.9 & 73.3 & $\begin{array}{c}\text { Nam et al. } \\
{[37]}\end{array}$ \\
$\begin{array}{l}\text { tomography/CT (FDG- } \\
\text { PET/CT) }\end{array}$ & & & \\
\hline
\end{tabular}

cancer [27]. CT has lower soft tissue contrast compared to MRI and, therefore, has not been widely used to differentiate benign from malignant lesions [28]. Early stages of ovarian cancer can be missed by CT imaging [29]. Although CT is widely used in ovarian cancer, its role lies in disease staging rather than in determining the nature of an adnexal mass, and the reported sensitivities are lower than for US and MRI (Tables 2, 3). In the last decade, the introduction of ${ }^{18}$ F-fluoro-deoxyglucose PET $\left({ }^{18} \mathrm{~F}\right.$-FDG PET) has changed diagnostic imaging in gynecologic oncology. This technique is based on "functional" imaging which makes use of the biologic characteristics of tumor cells. The elevated glucose metabolism in most tumor cells causes increased accumulation of FDG (a glucose analog). This radiopharmaceutical molecule competes with glucose for transport into the cell. FDG is a good radiotracer and is significantly increased in tumor cells; however, it is not specific for malignancy [30]. Physiological uptake into the ovaries and uterus during certain phases of the menstrual cycle is normal [31-33]. The introduction of combined FDG-PET/CT scanners allows accurate anatomic definition of areas of increased FDG uptake and, therefore, enables improved differentiation between benign and malignant lesions. Combined FDG-PET/CT scanners are, therefore, being considered a potentially useful tool for the characterization of adnexal masses. Only very few studies have been published so far regarding this subject and have shown high sensitivities but also high probabilities of producing false negative results in cases of borderline tumors, low-grade tumors, and early adenocarcinomas (Table 2) [34-36]. Although this technique is promising, it does not give enough additional information in the characterization of adnexal masses compared to US and is not widely available. Furthermore, the costs of such an examination are higher than those of US, CT and MRI (Table 3). 
Table 3 Comparison of different imaging methods for application in ovarian cancer patients

\begin{tabular}{|c|c|c|c|c|}
\hline & US & $\mathrm{CT}$ & MRI & $\mathrm{PET} / \mathrm{CT}$ \\
\hline Costs (approx.) & $1 \times$ & $2 \times$ & $4 \times$ & $6 \times$ \\
\hline Availability & Universal & Most hospitals & $\begin{array}{l}\text { Specialized centers, such as } \\
\text { university hospitals }\end{array}$ & $\begin{array}{l}\text { Specialized centers, such as } \\
\text { university hospitals }\end{array}$ \\
\hline $\begin{array}{l}\text { Main use in } \\
\text { ovarian cancer }\end{array}$ & $\begin{array}{l}\text { Detection and } \\
\text { classification of } \\
\text { adnexal masses }\end{array}$ & Staging and recurrence & $\begin{array}{l}\text { If mass unclassified by } \\
\text { ultrasound, if contraindication } \\
\text { for CT }\end{array}$ & $\begin{array}{l}\text { Undefined recurrent disease } \\
\text { (?) }\end{array}$ \\
\hline $\begin{array}{l}\text { Radiation } \\
\text { exposure }\end{array}$ & None & $10-30 \mathrm{mSv}$ & None & $10-30 \mathrm{mSv}$ \\
\hline $\begin{array}{l}\text { Exam duration } \\
\text { (approx. } \\
\text { minutes) }\end{array}$ & 20 & 1 & 30 & 30 (+60 min rest) \\
\hline $\begin{array}{l}\text { Use of intravenous } \\
\text { contrast agents }\end{array}$ & None & Iodine-based & Gadolinium-based & FDG-Radiotracer \\
\hline $\begin{array}{l}\text { Preparation before } \\
\text { imaging }\end{array}$ & Empty bladder & None & None & $\begin{array}{l}4 \text { h fasting physical rest } \\
60 \mathrm{~min}\end{array}$ \\
\hline $\begin{array}{l}\text { Limitations for } \\
\text { application }\end{array}$ & None & $\begin{array}{l}\text { Renal insufficiency, } \\
\text { hyperthyroidism, iodine } \\
\text { allergy }\end{array}$ & $\begin{array}{l}\text { Claustrophobia, cardiac } \\
\text { pacemaker, metallic implants }\end{array}$ & $\begin{array}{l}\text { Renal insufficiency, } \\
\text { hyperthyroidism iodine } \\
\text { allergy }\end{array}$ \\
\hline
\end{tabular}

\section{Preoperative staging of ovarian cancer and assessment of operability}

At present, surgical staging remains the gold standard for staging ovarian cancer and cannot be replaced by any of the available imaging techniques. However, most gynecological oncological surgeons request a detailed US by a specialist or cross-sectional imaging before the surgery to plan staging laparotomy. The goal is to optimize information regarding the patient's situation prior to surgery, to estimate the duration and extent of the laparotomy and to prepare for/prevent associated morbidity. Since neoadjuvant chemotherapy prior to debulking surgery has shown similar results to primary staging laparotomy in advanced ovarian cancer [38], one can speculate that the role of staging will become even more important in the future if treatment options based on diagnostic imaging can be discussed. The staging of ovarian cancer involves the assessment of the local tumor extent (for example, involvement of the pelvic ureter or uterus), the presence of peritoneal tumor deposits on bowel and mesentery, the description of unusual disease patterns that suggest non-ovarian cancer, and the presence of metastasis to lymph nodes, omentum, liver, spleen and distant metastasis. Staging requires, at a minimum, the complete assessment of the abdomen and pelvis [39].

The role of US in staging and assessment of operability and surveillance after initial therapy

Over the last decade, there have been massive improvements made regarding US techniques. It is a commonly available, non-invasive and comparatively inexpensive imaging method that can be carried out without any risk or discomfort for the patient. If performed by an experienced sonographer, it has an invaluable role not only in the primary diagnosis of gynecological cancers but also in the assessment of tumor extent in the pelvic and abdominal cavity and in the evaluation of treatment effect and followup [40]. In particular, the issue of cost has led some clinicians and sonographers to re-analyze the diagnostic capability of US in the evaluation of tumor staging [41]. Fischerova et al. [42] analyzed the ability of US to predict operability in ovarian cancer cases. They showed that using US criteria of operability to indicate the use of neoadjuvant chemotherapy prior to surgery in advanced ovarian cancer patients significantly increased the rate of optimal surgical cytoreduction [42]. US has the advantage to be a dynamic and interactive exam that can provide site-specific tenderness and can provide information how pelvic structures move in relation to each other [41]. Although other imaging techniques play a more prominent role in staging and follow-up in most Western countries where CT is widely available, US can provide important morphologic information that cannot be assessed by any other imaging method. One example is the morphological characterization of enlarged lymph nodes. While MRI and CT diagnose infiltrated lymph nodes mainly based on their size, US can differentiate metastatic from reactive lymph nodes based on sonomorphological and vascular patterns [41]. A recent publication on this topic illustrates how US can answer almost any specific question regarding disease extent if the patient is scanned systematically and thoroughly with 
transabdominal, transvaginal, and transrectal US probes [40].

One clear indication for US in the surveillance and diagnosis of recurrent disease involves conservatively managed ovarian borderline tumors. In these cases, transvaginal US was the most important imaging tool to detect recurrence in routine long-term follow-up programs [43, 44].

The role of other imaging methods in staging and assessing operability and surveillance after initial therapy

At present, contrast-enhanced CT is the most important and standard imaging method for preoperative evaluation and postoperative surveillance of ovarian cancer [45]. It is used to evaluate local tumor extent, operability and recurrence. In the literature, staging accuracy of CT ranges from 53 to $92 \%$, compared to 78-88 \% for MRI [46-48]. Although MRI has certain advantages over CT, such as higher soft tissue contrast and no radiation exposure for the patients, its applicability is limited because the use of intraluminal gastrointestinal contrast agents with MRI is not as routine as with CT (Table 3). MRI is generally more expensive than $\mathrm{CT}$, and patient motion can be a significant problem with MRI. However, MRI is recommended for patients with a contraindication for the use of iodinated contrast agents, pregnant patients, patients of childbearing age with borderline tumors (to minimize ionizing radiation exposure) and patients with inconclusive CT findings (Table 3) [45]. One of the limitations of CT is that the sensitivity of detecting implants of $<1 \mathrm{~cm}$ diameter is only $25-50 \%$ [49].

FDG-PET/CT is increasingly being used as an additional imaging method for initial staging, but also more importantly for the surveillance and the detection of recurrent disease [50]. Recent studies have demonstrated a benefit compared to $\mathrm{CT}$ in the detection of recurrent disease $[35,51]$. In combination with CA125, the detection rates for recurrence with FDG-PET/CT have been shown to be as high as $97.8 \%$ [52]. If recurrent disease is present, FDG-PET/CT is helpful in optimizing the selection of patients for site-specific treatment, including radiation treatment planning, and aided in the selection of optimal surgical candidates [53]. Since ovarian cancer has a relatively high risk of recurrence, PET-CT might become a relevant tool in the follow-up of ovarian cancer patients.

\section{Conclusion}

US is the method of choice for the initial evaluation of an adnexal mass, estimating the risk of malignancy and determining its site of origin. It is the only widely available, inexpensive and risk-free imaging technique that can give tissue-specific information in relation to each other and offer such high morphological differentiation. Its role in surveillance is limited but feasible in the hand of an experienced sonographer. It remains the method of choice for detecting disease recurrence in conservatively managed borderline ovarian tumors. We hope to find evidence for the benefit of ultrasound as a screening tool for ovarian cancer in high-risk women in the near future.

CT scan is the standard for preoperative staging of ovarian cancer but is limited in detecting metastatic lesions smaller than $1 \mathrm{~cm}$ in diameter and is also known to underestimate tumor stage. It is the standard imaging method for detecting recurrent disease. MRI can give important additional information in the characterization of adnexal masses that cannot be classified with ultrasound alone and is an equivalent alternative to CT in defining tumor stage and detecting recurrent disease. It is used especially in patients that have contraindications for CT.

FDG-PET/CT is the newest of the described imaging methods, which combines metabolic and anatomic imaging. It shows promising results not only as an additional method in disease staging but also in the detection of recurrent disease. Its role in ovarian cancer imaging remains to be defined.

Acknowledgments The authors thank Dr. Dorothy Huang, Dr. André Fedier and Dr. Hans Ulrich Brauer for their critical review in the preparation of the manuscript.

Conflict of interest The authors declare that they had no financial support and that there is no conflict of interest.

\section{References}

1. Ferlay J, Autier P, Boniol M, Heanue M, Colombet M, Boyle P (2007) Estimates of the cancer incidence and mortality in Europe in 2006. Ann Oncol 18(3):581-592

2. Alsop K, Fereday S, Meldrum C, deFazio A, Emmanuel C, George J, Dobrovic A, Birrer MJ, Webb PM, Stewart C, Friedlander M, Fox S, Bowtell D, Mitchell G (2012) BRCA mutation frequency and patterns of treatment response in BRCA mutationpositive women with ovarian cancer: a report from the Australian ovarian cancer study group. J Clin Oncol 30(21):2654-2656

3. Earle CC, Schrag D, Neville BA, Yabroff KR, Topor M, Fahey A, Trimble EL, Bodurka DC, Bristow RE, Carney M, Warren JL (2006) Effect of surgeon specialty on processes of care and outcomes for ovarian cancer patients. J Natl Cancer Inst 98(3):172-180

4. Engelen MJ, van der Zee AG, de Vries EG, Willemse PH (2006) Debulking surgery for ovarian epithelial cancer performed by a gynaecological oncologist improved survival compared with less specialised surgeons. Cancer Treat Rev 32(4):320-323 
5. Woo YL, Kyrgiou M, Bryant A, Everett T, Dickinson HO (2012) Centralisation of services for gynaecological cancers-a Cochrane systematic review. Gynecol Oncol 126(2):286-290

6. Valentin L, Ameye L, Testa A, Lécuru F, Bernard JP, Paladini D, Van Huffel S, Timmerman D (2006) Ultrasound characteristics of different types of adnexal malignancies. Gynecol Oncol 102(1):41-48

7. Sharma A, Apostolidou S, Burnell M, Campbell S, Habib M, Gentry-Maharaj A, Amso N, Seif MW et al (2012) Risk of epithelial ovarian cancer in asymptomatic women with ultrasounddetected ovarian masses: a prospective cohort study within the UK collaborative trial of ovarian cancer screening (UKCTOCS). Ultrasound Obstet Gynecol 40(3):338-344

8. Timmerman D, Valentin L, Bourne TH, Collins WP, Verrelst H, Vergote I, International Ovarian Tumor Analysis (IOTA) Group (2000) Terms, definitions and measurements to describe the sonographic features of adnexal tumors: a consensus opinion from the international ovarian tumor analysis (IOTA) group. Ultrasound Obstet Gynecol 16(5):500-505

9. Timmerman D, Testa AC, Bourne T, Ameye L, Jurkovic D, Van Holsbeke C, Paladini D, Van Calster B, Vergote I, Van Huffel S, Valentin L (2008) Simple ultrasound-based rules for the diagnosis of ovarian cancer. Ultrasound Obstet Gynecol 31(6):681-690

10. Geomini P, Kruitwagen R, Bremer GL, Cnossen J, Mol BW (2009) The accuracy of risk scores in predicting ovarian malignancy: a systemic review. Obstet Gynecol 113(2 Pt 1):384-394

11. Jacobs I, Oram D, Fairbanks J, Turner J, Frost C, Grudzinskas JG (1990) A risk of malignancy index incorporating CA 125, ultrasound and menopausal status for the accurate preoperative diagnosis of ovarian cancer. Br J Obstet Gynecol 97(10):922-929

12. Chia YN, Marsden DE, Robertson G, Hacker NF (2008) Triage of ovarian masses. Aust N Z J Obstet Gynaecol 48(3):322-328

13. Timmerman D, Testa AC, Bourne T, Ferrazzi E, Ameye L, Konstantinovic ML, Van Calster B, Collins WP, Vergote I, Van Huffel S, Valentin L (2005) Logistic regression model to distinguish between the benign and malignant adnexal mass before surgery: a multicenter study by the international ovarian tumor analysis group. J Clin Oncol 23(34):8794-8801

14. Valentin L, Hagen B, Tingulstad S, Eik-Nes S (2001) Comparison of 'pattern recognition' and logistic regression models for discrimination between benign and malignant pelvic masses: a prospective cross validation. Ultrasound Obstet Gynecol 18(4):357-365

15. Van Holsbeke C, Van Calster B, Bourne T, Ajossa S, Testa AC, Guerriero S, Fruscio R, Lissoni AA, Czerkierdowski A, Savelli L, Van Huffel S, Valentin L, Timmerman D (2012) External validation of diagnostic models to estimate the risk of malignancy in adnexal masses. Clin Cancer Res 18(3):815-825

16. Van Calster B, Timmerman D, Valentin L, McIndoe A, GhaemMaghami S, Testa AC, Vergote I, Bourne T (2012) Triaging women with ovarian masses for surgery: observational diagnostic study to compare RCOG guidelines with an international ovarian tumour analysis (IOTA) group protocol. BJOG 119(6):662-671

17. Moore RG, McMeekin DS, Brown AK, DiSilvestro P, Miller MC, Allard WJ, Gajewski W, Kurman R, Bast RC Jr, Skates SJ (2009) A novel multiple marker bioassay utilizing HE4 and CA125 for the prediction of ovarian cancer in patients with a pelvic mass. Gynecol Oncol 112(1):40-46

18. Urban N, Thorpe JD, Bergan LA, Forrest RM, Kampani AV, Scholler N, O'Briant KC, Anderson GL, Cramer DW, Berg CD, McIntosh MW, Hartge P, Drescher CW (2011) Potential role of HE4 in multimodal screening for epithelial ovarian cancer. J Natl Cancer Inst 103(21):1630-1634

19. Karlsen MA, Sandhu N, Høgdall C, Christensen IJ, Nedergaard L, Lundvall L, Engelholm SA, Pedersen AT, Hartwell D,
Lydolph M, Laursen IA, Høgdall EV (2012) Evaluation of HE4, CA125, risk of ovarian malignancy algorithm (ROMA) and risk of malignancy index (RMI) as diagnostic tools of epithelial ovarian cancer in patients with a pelvic mass. Gynecol Oncol 127(2):379-383

20. Jacob F, Meier M, Caduff R, Goldstein D, Pochechueva T, Hacker N, Fink D, Heinzelmann-Schwarz V (2011) No benefit from combining HE4 and CA125 as ovarian tumor markers in a clinical setting. Gynecol Oncol 121(3):487-491

21. Campbell S (2012) Ovarian cancer: role of ultrasound in preoperative diagnosis and population screening. Ultrasound Obstet Gynecol 40(3):245-254

22. Reade CJ, Riva JJ, Busse JW, Goldsmith CH, Elit L (2013) Risks and benefits of screening asymptomatic women for ovarian cancer: a systematic review and meta-analysis. Gynecol Oncol 130(3):674-681

23. Long KC, Kauff ND (2013) Screening for familial ovarian cancer: a ray of hope and a light to steer by. J Clin Oncol 31(1):8-10

24. Mohaghegh P, Rockall AG (2012) Imaging strategy for early ovarian cancer: characterization of adnexal masses with conventional and advanced imaging techniques. Radiographics 32(6): 1751-1773

25. Timmerman D, Schwärzler P, Collins WP, Claerhout F, Coenen M, Amant F, Vergote I, Bourne TH (1999) Subjective assessment of adnexal masses with the use of ultrasonography: an analysis of interobserver variability and experience. Ultrasound Obstet Gynecol 13:11-16

26. Dodge JE, Covens AL, Lacchetti C, Elit LM, Le T, DevriesAbound M, Fung-Kee-Fung M, Gynecology Cancer Disease Site Group (2012) Management of a suspicious adnexal mass: a clinical practice guideline. Curr Oncol 19(4):244-257

27. Kinkel K, Lu Y, Mehdizade A, Pelte MF, Hricak H (2005) Indeterminate ovarian mass at US: incremental value of second imaging test for characterization-meta-analysis and Bayesian analysis. Radiology 236(1):85-94

28. Bharwani N, Reznek RH, Rockall AG (2011) Ovarian cancer management: the role of imaging and diagnostic challenges. Eur J Radiol 78(1):41-51

29. Alt CD, Brockner KA, Eichbaum M, Sohn C, Arnegger FU, Kauczor HU, Hallscheidt P (2011) Imaging of female pelvic malignancies regarding MRI, CT, and PET/CT: part 2. Strahlenther Onkol 187(11):705-714

30. Basu S, Kwee TC, Surti S, Akin EA, Yoo D, Alavi A (2011) Fundamentals of PET and PET/CT imaging. Ann N Y Acad Sci 1228:1-18

31. Nishizawa S, Inubushi M, Ozawa F, Kido A, Okada H (2007) Physiological FDG uptake in the ovaries after hysterectomy. Ann Nucl Med 21(6):345-348

32. Zhu ZH, Cheng WY, Cheng X, Dang YH (2007) Characteristics of physiological uptake of uterus and ovaries on $18 \mathrm{~F}$-fluorodeoxyglucose positron emission tomography. Zhongguo Yi Xue Ke Xue Yuan Xue Bao 29(1):124-129

33. Iyer RB, Balachandran A, Devine CE (2007) PET/CT and cross sectional imaging of gynecologic malignancy. Cancer Imaging 7 (Spec No A):S130-S138

34. Castellucci P, Perrone AM, Picchio M, Ghi T, Farsad M, Nanni C, Messa C, Meriggiola MC, Pelusi G, Al-Nahhas A, Rubello D, Fazio F, Fanti S (2007) Diagnostic accuracy of 18F-FDG PET/CT in characterizing ovarian lesions and staging ovarian cancer: correlation with transvaginal ultrasonography, computed tomography, and histology. Nucl Med Commun 28(8):589-595

35. Risum S, Høgdall C, Loft A, Berthelsen AK, Høgdall E, Nedergaard L, Lundvall L, Engelholm SA (2007) The diagnostic value of PET/CT for primary ovarian cancer-a prospective study. Gynecol Oncol 105(1):145-149 
36. Yamamoto Y, Oguri H, Yamada R, Maeda N, Kohsaki S, Fukaya T (2008) Preoperative evaluation of pelvic masses with combined $18 \mathrm{~F}$-fluorodeoxyglucose positron emission tomography and computed tomography. Int J Gynaecol Obstet 102(2):124-127

37. Nam EJ, Yun MJ, Oh YT, Kim JW, Kim JH, Kim S, Jung YW, Kim SW, Kim YT (2010) Diagnosis and staging of primary ovarian cancer: correlation between PET/CT, Doppler US, and CT or MRI. Gynecol Oncol 116(3):389-394

38. Vergote I, Tropé CG, Amant F, Kristensen GB, Ehlen T, Johnson $\mathrm{N}$, Verheijen $\mathrm{RH}$, van der Burg ME, Lacave AJ, Panici PB, Kenter GG, Casado A, Mendiola C, Coens C, Verleye L, Stuart GC, Pecorelli S, Reed NS, European Organization for Research and Treatment of Cancer-Gynaecological Cancer Group; NCIC Clinical Trials Group (2010) Neoadjuvant chemotherapy or primary surgery in stage IIIC or IV ovarian cancer. N Engl J Med 363(10):943-953

39. Forstner R (2007) Radiological staging of ovarian cancer: imaging findings and contribution of CT and MRI. Eur Radiol 17(12):3223-3235

40. Fischerova D (2011) Ultrasound scanning of the pelvis and abdomen for staging of gynecological tumors: a review. Ultrasound Obstet Gynecol 38(3):246-266

41. Testa AC, Bourne TH (2009) Characterising pelvic masses using ultrasound. Best Pract Res Clin Obstet Gynaecol 23(5):725-738

42. Fischerova D, Cibula D, Dundr P, Zikan M, Freitag P, Slama J, Calda P (2008) The role of ultrasound in prediction of optimal versus suboptimal cytoreductive surgery in advanced ovarian cancers OC 132: 18th World congress on ultrasound in obstetrics and gynecology. Ultrasound Obstet Gynecol 32:243-307

43. Uzan C, Kane A, Rey A, Gouy S, Pautier P, Lhomme C, Duvillard P, Morice P (2011) How to follow up advanced-stage borderline tumours? Mode of diagnosis of recurrence in a large series stage II-III serious borderline tumours of the ovary. Ann Oncol 22(3):631-635

44. Zanetta G, Rota S, Lissoni A, Meni A, Brancatelli G, Buda A (2001) Ultrasound, physical examination, and CA 125 measurement for the detection of recurrence after conservative surgery for early borderline ovarian tumors. Gynecol Oncol 81(1):63-66

45. Mitchell D, Javitt M, Glanc P, Bennett G, Brown D, Dubinsky T, Harisinghani M, Harris R, Horowitz N, Pandharipande P, Pannu H, Podrasky A, Royal H, Shipp T, Siegel C, Simpson L, WongYou-Cheong J, Zelop C (2012) Staging and follow-up of ovarian cancer ACR appropriateness criteria ${ }^{\circledR}$

46. Woodward PJ, Hosseinzadeh K, Saenger JS (2004) From the archives of the AFIP: radiologic staging of ovarian carcinoma with pathologic correlation. Radiographics 24(1):225-246

47. Forstner R, Hricak H, Occhipinti KA, Powell CB, Frankel SD, Stern JL (1995) Ovarian cancer: staging with CT and MR imaging. Radiology 197(3):619-626

48. Tempany CM, Zou KH, Silverman SG, Brown DL, Kurtz AB, McNeil BJ (2000) Staging of advanced ovarian cancer: comparison of imaging modalities-report from the radiological diagnostic oncology group. Radiology 215(3):761-767

49. Coakley FV, Choi PH, Gougoutas CA, Pothuri B, Venkatraman E, Chi D, Bergman A, Hricak H (2002) Peritoneal metastases: detection with spiral CT in patients with ovarian cancer. Radiology 223(2):495-499

50. Sebastian S, Lee SI, Horowitz NS, Scott JA, Fischman AJ, Simeone JF, Fulle AF, Hahn PF (2008) PET-CT versus CT alone in ovarian cancer recurrence. Source Abdomen Imaging 33(1):112-118

51. Markman M (2009) Optimal management of recurrent ovarian cancer. Int J Gynecol Cancer 19(Suppl 2):S40-S43

52. Murakami M, Miyamoto $\mathrm{T}$, Iida $\mathrm{T}$, Tsukada $\mathrm{H}$, Watanabe $\mathrm{M}$, Shida M, Maeda H, Nasu S, Yasuda S, Yasuda M, Ide M (2006) Whole-body positron emission tomography and tumor marker CA125 for detection of recurrence in epithelial ovarian cancer. Int J Gynecol Cancer 16(1):99-107

53. Thrall MM, DeLoia JA, Gallion H, Avril N (2007) Clinical use of combined positron emission tomography and computed tomography (FDG-PET/CT) in recurrent ovarian cancer. Gynecol Oncol 105(1):17-22 